\title{
ALIMENTAÇÃO ESCOLAR E DESENVOLVIMENTO SOCIAL LOCAL: O CASO DA AQUISIÇÃO DE GÊNEROS DA AGRICULTURA FAMILIAR
}

\author{
GOMES, Ludmir dos Santos (Brasil, Ceará, Fortaleza) ${ }^{1 *}$; \\ BEZERRA, José Arimatea Barros (Brasil, Ceará, Fortaleza) ${ }^{1+*}$ \\ ${ }^{1}$ Universidade Federal do Ceará \\ ORCID ID: https://orcid.org/0000-0001-9297-9719 \\ ORCID ID: https://orcid.org/0000-0001-8276-3834*
}

\begin{abstract}
RESUMO
Estudo sobre o fornecimento de alimentos da agricultura familiar para o Programa Nacional de Alimentação Escolar. Objetiva-se analisar a relação entre a logística empregada pelos agricultores familiares e o propósito do referido programa relacionado ao desenvolvimento econômico e social local. Os dados foram coletados por meio de entrevistas com agricultores familiares que fornecem gêneros alimentícios para o Programa Nacional de Alimentação Escolar e observações de suas práticas no âmbito de municípios do Ceará. As bases teóricas da pesquisa foram estudos sobre logística, a história e os fundamentos legais do programa. Os resultados permitem afirmar que a logística de fornecimento, os aspectos burocráticos e o planejamento inadequado dos agricultores diminuem a participação esperada dessa categoria de produtores como fornecedores da alimentação escolar dentro do percentual mínimo obrigatório e das condições exigidas por lei. Portanto, o propósito do referido programa de contribuir para o desenvolvimento econômico e social local não se realiza de forma plena.
\end{abstract}

\section{PALAVRAS-CHAVE}

Alimentação escolar. Agricultura familiar. Desenvolvimento econômico e social local. Logística de alimentos. Interdisciplinaridade.

\section{SCHOOL NOURISHMENT AND LOCAL SOCIAL DEVELOPMENT:} THE CASE OF FOOD STUFF ACQUISITION FROM FAMILIAR FARMING

\footnotetext{
ABSTRACT

Study on the supply of food from family agriculture to the National School Feeding Program. The objective is to analyze the relationship between the logistics employed by family farmers and the purpose of the said program related to local economic and social development. Data were collected through interviews with family farmers supplying foodstuffs for the National School Feeding Program and observations of their practices within the municipalities of Ceará. The theoretical bases of the research were studies on logistics, history and legal grounds of the program. The results allow us to affirm that supply logistics, bureaucratic aspects and inadequate planning of farmers reduce the expected participation of this category of producers as suppliers of school feeding within the minimum required percentage and the conditions required by law. Therefore, the purpose of said program to contribute to local economic and social development is not fully realized.
}

Educação \& Formação, Fortaleza, v. 4, n. 11, p. 97-116, maio/ago. 2019 


\title{
KEYWORDS
}

School nourishment. Familiar farming. Local social development. Food logistics. Interdisciplinarity.

\section{ALIMENTACIÓN ESCOLAR Y DESARROLLO SOCIAL LOCAL: EL CASO DE LA ADQUISICIÓN DE GÉNEROS DE LA AGRICULTURA FAMILIAR}

\begin{abstract}
RESUMEN
Estudio sobre el suministro de alimentos de la agricultura familiar para el Programa Nacional de Alimentación Escolar. Se pretende analizar la relación entre la logística empleada por los agricultores familiares y el propósito del referido programa relacionado al desarrollo económico y social local. Los datos fueron recolectados por medio de entrevistas con agricultores familiares que suministran productos alimenticios para el Programa Nacional de Alimentación Escolar y observaciones de sus prácticas en el ámbito de municipios de Ceará. Las bases teóricas de la investigación fueron estudios sobre logística, la historia y los fundamentos legales del programa. Los resultados permiten afirmar que la logística de suministro, los aspectos burocráticos y la planificación inadecuada de los agricultores disminuyen la participación esperada de esa categoría de productores como proveedores de la alimentación escolar dentro del porcentaje mínimo obligatorio y de las condiciones exigidas por la ley. Por lo tanto, el propósito del referido programa de contribuir al desarrollo económico y social local no se realiza de forma plena.
\end{abstract}

\section{PALABRAS CLAVE}

Alimentación escolar. Agricultura familiar. Desarrollo económico y social local. Logística de alimentos. Interdisciplinariedad.

\section{INTRODUÇÃO}

O presente estudo aborda a temática venda de alimentos para o Programa Nacional de Alimentação Escolar (PNAE), que é a mais antiga e mais ampla política de alimentação e nutrição do Estado brasileiro, criada em 31 de março de 1955. Segundo Bezerra (2003), a evolução dessa política, em termos de abastecimento, passou por diferentes fases, a saber: a internacional (1955-1973), a nacional centralizada (19731993) e a nacional descentralizada (1993-dias atuais). Iniciou-se e teve parte de seu percurso caracterizado por doações de gêneros alimentícios por instituições internacionais, como o Fundo das Nações Unidas para a Infância e Adolescência (Unicef), o Fundo das Nações Unidas para a Agricultura e Alimentação (FAO) e o 
Programa Alimentos para a Paz. Atualmente funciona com suprimento de alimentos produzidos no Brasil.

Conforme o Fundo Nacional de Desenvolvimento da Educação (FNDE), autarquia do governo federal que faz a gestão e financia o programa, em 2015 foram investidos 3,759 bilhões de reais na oferta de alimentação para 41,5 milhões de alunos da educação básica da rede pública de ensino, em 200 dias do ano letivo escolar (BRASIL, 2016). Trata-se, então, de uma política pública cuja operacionalização, em se tratando de aquisição de alimentos, necessita de uma logística sistemática e criteriosa, principalmente em termos de aquisição de produtos in natura tanto da agricultura convencional e principalmente da agricultura familiar.

$O$ arcabouço legal que rege o PNAE tem como normativa principal a Lei $n$. 11.947, de 16 de junho de 2009. Conforme o artigo 14 dessa lei, do total dos recursos financeiros repassados pelo FNDE no âmbito do PNAE para as Entidades Executoras (EEx) - estados, municípios e Distrito Federal -, no mínimo 30\% deverão ser utilizados na aquisição de gêneros alimentícios diretamente da agricultura familiar e suas organizações (BRASIL, 2009).

A determinação de compra da agricultura familiar tem como fins o seguinte: aquisição de produtos locais e regionais in natura, oferta de alimentação saudável para os alunos beneficiários, valorização da produção agrícola local e regional e respectivo desenvolvimento econômico, social e cultural desses espaços.

A partir dessa realidade de aquisição de produtos de gêneros alimentícios locais e regionais, este estudo realizou uma análise da logística envolvida nesse processo guiado pelas seguintes questões: quais as modalidades de transporte utilizadas? Quais são as modalidades mais adequadas? $\mathrm{E}$ as inadequadas? Quais as dificuldades logísticas enfrentadas pelos agricultores familiares cearenses para venda, transporte e entrega, considerando as regras do PNAE? Como essas dificuldades são superadas? Até que ponto tais obstáculos logísticos interferem na concretização dos fins supracitados?

Essas questões partem da seguinte hipótese: a logística de transporte dos gêneros alimentícios utilizada pelos agricultores interfere na concretização dos objetivos de desenvolvimento econômico e social local e na efetivação do preceito legal de aplicação mínima de 30\% dos recursos do PNAE na agricultura familiar. 
Em busca da comprovação da hipótese acima, o estudo se guiou pelo seguinte objetivo geral: analisar a relação entre a logística empregada pelos agricultores familiares cearenses e a concretização do propósito do PNAE de desenvolvimento econômico e social local.

O interesse pelo tema logística da alimentação escolar foi decorrente de atividades de extensão e pesquisa desenvolvidas no Centro Colaborador em Alimentação e Nutrição do Escolar (Cecane) da Universidade Federal do Ceará (UFC), que faz parte de um acordo de colaboração entre o FNDE e a UFC. Durante os anos de 2016 e 2017, desempenharam-se ações vinculadas à formação de atores sociais do PNAE atuantes em municípios do estado do Ceará. O assunto agricultura familiar fez parte do programa das formações, gerando muito interesse dos participantes, uma vez que faz parte da realidade cotidiana de quem trabalha com alimentação escolar. Então, pode-se constatar a importância da logística no processo de aquisição de gêneros alimentícios da agricultura familiar.

Tendo em vista o objetivo supracitado, a pesquisa realizada teve como base um estudo de caso de fornecimento de alimentos para o PNAE por agricultores familiares em duas situações possíveis, conforme diretrizes legais do Programa: venda por meio de Declaração de Aptidão ao Pronaf - DAP1 Jurídica e do fornecimento através de DAP Física. Os instrumentos de coleta de dados foram estes: entrevistas semiestruturadas aplicadas com diretores de uma cooperativa de agricultores, representativo de DAP Jurídica e agricultores individuais (DAP Física) e observações de suas práticas de venda de gêneros alimentícios para o PNAE. Por razões éticas, os nomes das pessoas e instituições que colaboraram na pesquisa foram mantidos no anonimato (GOMES, 2017).

Foram entrevistados dois diretores de uma cooperativa de agricultores familiares, portadora de DAP Jurídica, e cinco agricultores familiares (DAP Física), seguindo-se o seguinte roteiro: o tipo de transporte utilizado para a entrega dos gêneros; as dificuldades encontradas para a venda, transporte e entrega dos alimentos ao PNAE; as estratégias utilizadas para enfrentar as dificuldades. Realizou-se a observação

\footnotetext{
1 A Declaração de Aptidão ao Programa Nacional de Fortalecimento da Agricultura Familiar (Pronaf) é a forma de reconhecimento do agricultor familiar individual (DAP Física) e suas organizações (DAP Jurídica) pelo Ministério do Desenvolvimento Agrário (MDA). É o instrumento de identificação desse segmento de produtores de alimentos utilizado para o acesso às políticas públicas. A DAP Física identifica o produtor individual e sua família. A DAP Jurídica identifica as formas associativas dos agricultores familiares, organizados em pessoas jurídicas devidamente formalizadas (BRASIL, 2017).
}

Educação \& Formação, Fortaleza, v. 4, n. 11, p. 97-116, maio/ago. 2019

DOI: https://doi.org/10.25053/redufor.v4i11.899

http://seer.uece.br/redufor 
participante de quatro eventos de transporte e entrega de alimentos ao PNAE, sendo um feito pela cooperativa e três por agricultores individuais.

A pesquisa foi de natureza qualitativa, cujos dados empíricos foram analisados a partir de referenciais teóricos de logística, de estudos de enfoque histórico e político e das bases legais do PNAE.

\section{A LOGÍSTICA DE DISTRIBUIÇÃO DE ALIMENTOS AO LONGO DA HISTÓRIA DA POLÍTICA DE ALIMENTAÇÃO ESCOLAR NO BRASIL}

Conforme já afirmado, a política de alimentação escolar passou por três fases, a saber: internacional (1955-1973), nacional centralizada (1973-1993) e nacional descentralizada (1994-atual). Considerando o período da alimentação escolar em sua fase internacionalizada, a distribuição de alimentos aconteceu tendo como fonte principal "doações provenientes de organismos internacionais". Predominavam problemas relacionados à logística de distribuição, uma vez que os produtos chegavam do exterior à capital do país para, em seguida, serem distribuídos aos estados e municípios.

Inúmeros fatores contribuíram para a distribuição irregular e inadequada dos alimentos: os governos estaduais e municipais atrasavam suas contrapartidas de contribuição, faltavam locais adequados para o depósito e armazenamento dos gêneros, bem como meios de transporte apropriados.

A logística dessa política de alimentação naquela época (1955) era muito complexa, de difícil operacionalização e onerosa, por não contar com a tecnologia dos dias atuais. Toda a sua sistemática de documentação e controle era feita de forma manual, com formulários contínuos carbonizados e datilografados. Ademais, a fiscalização era feita pelo Ministério da Agricultura, após a mercadoria chegar ao Brasil e passar por todo o processo alfandegário. Essa logística continuava na complexa distribuição para os estados e municípios. Prevaleciam os alimentos formulados, principalmente o leite em pó (BEZERRA, 2003).

A fase nacional centralizada iniciou-se com o fim da ajuda internacional, quando - Brasil começou a reformular a Campanha Nacional de Alimentação Escolar (CNAE), aproximando-se das indústrias alimentícias aqui localizadas. Nesse sentido, duas linhas de ação foram colocadas em prática. A primeira foi a busca de racionalização e 
eficiência na operação da Campanha, diminuindo sua máquina administrativa por meio de redução de órgãos e recursos humanos. A segunda constituiu-se de acordo com as indústrias alimentícias internas para o fornecimento dos gêneros. Mudava tanto a origem dos alimentos como a composição das cestas dos produtos, nas quais os alimentos formulados passaram rapidamente a ocupar o lugar mais importante. Esses alimentos se caracterizavam pelo longo prazo de validade e alto teor de conservantes.

Emerge, dessa forma, um subsetor da indústria alimentícia para satisfazer a demanda da CNAE. Contudo, a logística de distribuição permanece sem alterações significativas (COIMBRA; MEIRA; STARLING, 1982). Inicia-se, assim, a fase nacional da alimentação escolar, que, durante as décadas de 1970 e 1980, desenvolveu-se de forma bastante irregular, com interrupções no fornecimento do alimento nas escolas e com o atendimento apenas parcial da clientela a quem deveria assistir.

Em termos de abrangência, na segunda metade da década de 1980, a merenda escolar ampliou-se, tendo sido praticamente universalizada na zona urbana, onde, em $92 \%$ das escolas, havia merenda. Barreira (1991) relata que, em quase $85 \%$ das escolas rurais, ela também existia. Porém, a irregularidade na distribuição era 0 principal problema, principalmente nas escolas do Norte e Nordeste.

A partir de 1993, a fase nacional descentralizada começou como uma das metas principais do Plano de Combate à Fome e à Miséria do governo Itamar Franco. Troca-se novamente de nome: de Campanha Nacional de Alimentação Escolar (CNAE) para Programa Nacional de Alimentação Escolar (PNAE). Partindo do princípio de adesão voluntária e optativa, o processo de descentralização do Programa aconteceu em duas etapas. No primeiro semestre do mesmo ano, o convênio foi feito com os municípios com mais de 50 mil habitantes, incluindo-se aqueles que haviam participado de uma experiência de municipalização ocorrida nos anos 1980. Mas problemas anteriores continuaram (BEZERRA, 2003).

No Ceará, o primeiro semestre do ano de 2000 foi marcado por uma série de denúncias nos jornais locais acerca de irregularidades relacionadas à merenda escolar: desvio de recursos, favorecimento de empresas de pessoas ligadas a prefeitos, irregularidades de empresas fornecedoras, superfaturamento, desperdício, encarecimento dos alimentos pela ação de atravessadores, comida estocada no chão e em banheiros de escolas, falta de fiscalização, etc. Foi proposta, na Assembleia 
Legislativa do Ceará (Alece), a criação de uma Comissão Parlamentar de Inquérito (CPI), que não foi instalada, uma vez que tais denúncias envolviam muitos prefeitos da base de apoio do governo estadual da época, que, por sua vez, tinha apoio da maioria dos deputados nesse parlamento (BEZERRA, 2009).

Ainda sobre problemas, persistia a deficiência de infraestrutura de operacionalização dessa política, como locais de armazenagem inexistentes ou inadequados, dificuldades de transporte, carência de equipamentos destinados à conservação e preparo dos alimentos, o que se deve ao fato de as escolas ainda não terem sua estrutura física adaptada à nova realidade.

Assim, evidencia-se um problema, dentre os referidos acima, que interessa a este estudo: os aspectos logísticos do PNAE, no seu formato, com foco na sistemática de compra da agricultura familiar.

Houve um crescimento do PNAE nos últimos anos, considerado como a política pública em alimentação e nutrição mais abrangente e duradoura na área de alimentação escolar do mundo. Também cresceu a cobertura populacional. Entre 1995 e 2010, o atendimento do PNAE passou de 33,2 milhões para 45,6 milhões de escolares, e os recursos financeiros passaram de 590,1 milhões para três bilhões de reais. Existiram outros avanços, como o papel dos conselheiros de alimentação escolar, as ações de nutricionistas e do responsável técnico dos Cecanes (PEIXINHO, 2013).

Vale ressaltar a importância e o papel desses colaboradores para o campo da política nacional de alimentação escolar, tanto que, a partir de 2003, o governo brasileiro começou a apoiar o desenvolvimento de programas de alimentação escolar no âmbito da América Latina, Caribe, África e Ásia.

A partir de 2003, a Coordenação Geral do PNAE (CGPAE) iniciou uma reestruturação de seus objetivos, diretrizes e estruturas técnicas e operacionais para a gestão e a execução da alimentação escolar: equidade, universalidade, sustentabilidade, continuidade, direito humano à alimentação adequada e respeito aos hábitos e tradições regionais.

Entre 2003 e 2010, inúmeros avanços puderam ser verificados. Foram estabelecidos critérios técnicos e operacionais tendo em vista flexibilidade, eficiência e eficácia da gestão do PNAE. Estimulou-se o controle social do Programa por meio dos 
Conselhos de Alimentação Escolar (CAE) e da normalização das ações e atribuições do nutricionista responsável técnico (PEIXINHO, 2013).

A grande conquista da política de alimentação escolar nesse período foi a aprovação da Lei n. 11.947, de 16 de junho de 2009. A alimentação escolar foi universalizada e estendida para toda a educação básica, educação infantil, ensino fundamental e médio e respectivas modalidades. Foi instituído apoio ao desenvolvimento sustentável com o incentivo à aquisição de gêneros alimentícios da agricultura familiar produzidos localmente (PEIXINHO, 2013). De acordo com a Lei n. 11.326/2006:

\section{É considerado agricultor familiar e empreendedor familiar rural aquele que pratica atividades no meio rural, possui área menor a 4 módulos fiscais, mão de obra da própria família, renda familiar vinculada ao próprio estabelecimento e gerenciamento do estabelecimento ou empreendimento pela própria família. Também são considerados agricultores familiares: silvicultores, aquicultores, extrativistas, pescadores, indígenas, quilombolas e assentados da reforma agrária.}

A partir de 2007, foram estabelecidas parcerias do FNDE com Instituições Federais de Ensino Superior (IFES), criando os Centros Colaboradores em Alimentação e Nutrição do Escolar (Cecane), que se constituem como centros de ensino, pesquisa e extensão, executando ações de formação de atores do PNAE, monitorando e assessorando os municípios na execução do Programa.

Antes de apresentar a descrição analítica da logística dessa política no caso em estudo, um município do estado Ceará, cabe explicitar alguns fundamentos de logística.

\section{FUNDAMENTOS TEÓRICOS E HISTÓRICOS SOBRE LOGÍSTICA}

A logística é um processo estratégico de gerência que envolve a aquisição, transporte e armazenamento de materiais com seus respectivos fluxos. Nos dias atuais, planejar e controlar estoques ainda se apresenta como um jogo complexo para a atividade de quem gerencia materiais (NOVAES, 2007).

Devido às variações de fatores que influenciam os custos relativos, a busca contínua por soluções que visem à redução dos custos e a eficiência dos controles, procura-se desenvolver métodos que satisfaçam as políticas das empresas.

Falar de logística implica considerar a cadeia de suprimento, pois, para o bom desempenho da primeira, é necessário que a segunda seja bem diluída. A cadeia de 
suprimentos é formada por fornecedores, manufatura, distribuição e consumidor, conforme se define em seguida.

Os fornecedores, sejam empresas, sejam pessoas, estão no início do processo de aquisição de materiais, componentes e suprimentos. A atividade logística busca incrementar as relações entre fornecedores e clientes, bem como, de forma estratégica, diminuir o custo e otimizar o tempo operacional (RAMOS, 2017). No caso em estudo, o PNAE, a opção por adquirir produtos locais da agricultura familiar se insere nessa lógica de redução de custos e aumento da qualidade, o que deve ocorrer pela redução da cadeia logística.

$\mathrm{Na}$ seleção de fornecedores, há elementos importantes que devem ser considerados, tais como o papel do fornecedor, a seleção inicial e as parcerias, com a busca de um diferencial competitivo. Devem ser considerados também o planejamento e controle dos estoques, os tipos e custos, o lote econômico, entre outras particularidades da gestão de estoques (RAMOS, 2017).

Um diferencial de destaque é o preço, que se articula com outros diferenciais, tais como a solicitação de compra e o ressuprimento até a entrega do produto ao consumidor final.

O fornecedor ideal é aquele que possui as condições e a tecnologia para fabricar o produto; no caso em estudo, os gêneros alimentícios com qualidade exigida nas quantidades necessárias e a venda a preços competitivos, o que lhe permite administrar o seu negócio com eficiência e lucratividade.

As manufatureiras são locais onde se produz e/ou onde está instalada a fábrica ou o centro de produção de alimentos. Com a definição do posicionamento da manufatureira, tem-se a definição de toda a política de estoques da empresa e a sistemática de entrega dos produtos e/ou gêneros alimentícios (RAMOS, 2017). No caso da alimentação escolar, quanto mais próximo o fornecedor está da escola/prefeitura, mais eficientes serão os resultados da logística, tendo em vista a qualidade dos alimentos fornecidos.

Para serem eficientes, as empresas de manufatura devem constantemente aumentar a eficiência tanto na cadeia de fornecimento quanto nos processos produtivos. Tais ganhos em eficiência podem ser acelerados quando se combinam com processos

Educação \& Formação, Fortaleza, v. 4, n. 11, p. 97-116, maio/ago. 2019 
documentais que permitem e capacitam em vez de dificultarem e drenarem recursos das empresas.

Os centros de distribuição são os locais de armazenamento dos produtos acabados, peças de reposição, gêneros alimentícios. Ou seja, muitas empresas chamam de depósito de mercadorias; porém, o termo mais adequado, nos estudos de logística, é "centro de distribuição", pois assume uma função importante no processo, que é a preocupação com o nível de serviço ofertado ao consumidor (RAMOS, 2017).

Contudo, não se pode exigir que uma empresa consiga atender plenamente a todos os mercados consumidores. Por isso, a atividade logística deve ater-se às definições de mercado, onde e como estes mercados serão atendidos. Assim, ocorre uma aproximação maior com os resultados concretos.

O consumidor é toda pessoa física ou jurídica que adquire ou utiliza produto ou serviço como destinatário final; no caso em estudo, o Programa de Alimentação Escolar, representado pelas Entidades Executoras (EEx). O consumidor é vinculado ao destinatário final, que adquire um produto ou serviço, ou que é beneficiário, no caso, os alunos.

Essas definições teóricas sobre logística se desenvolveram historicamente. Gomes e Ribeiro (2004) afirmam que o termo "logística" se origina do vocábulo francês "loger", com o sentido de alocar. As atividades logísticas teriam se iniciado na Grécia Antiga, nas operações militares, visando ao abastecimento dos exércitos com gêneros alimentícios, armas e munições, medicamentos, nas quantidades devidas e no momento apropriado. Os estudos sistemáticos sobre a temática se iniciam nos Estados Unidos da América no século XVIII, sendo que a primeira obra sobre o assunto foi publicada em 1917, com o título Logística pura: a ciência da preparação para a guerra.

Figueiredo e Arkader (1998) relatam que a logística se desenvolveu por cinco eras, a partir do início do século XX. A primeira era, designada como "Do campo ao mercado", com ênfase na economia agrária, abrange o período que vai do princípio do século XX ao início dos anos 1940, tendo como função o escoamento da produção agrícola. A segunda era, que vai de 1940 a 1960, chamada de "Era das especializações", com foco nos desempenhos funcionais ou movimentação de materiais - armamentos e transporte de bens. O período seguinte, "Integração interna", centra-se nas funções integradas: custo total, transportes, distribuição, armazenagem, estoque e 
manuseio de materiais, predominando entre o início dos anos 1960 e o princípio da década de 1970 (FIGUEIREDO; ARKADER, 1998).

Entre a década de 1970 à metade dos anos 1980, ocorre a era "Foco no cliente", cujo objetivo se voltava para a produtividade, custos de estoques e eficiência. Nesse momento, foi incluída como disciplina nos cursos de Administração de Empresas. Finalmente, nos dias atuais, predomina a "Logística como elemento diferenciador", ou Era do Supply Chain, que se centra na globalização, tecnologia da informação, responsabilidade social e ecologia (FIGUEIREDO; ARKADER, 1998).

Durante décadas, as práticas de logística estiveram ligadas à compra de materiais, estocagem e distribuição. Eram, assim, atividades de apoio sem acrescentarem valor ao produto, sem serem consideradas no planejamento e decisões estratégicas da empresa (NOVAES, 2007).

Historicamente as concepções e práticas logísticas se transformaram, tendo em vista interesses empresariais e clientelísticos. Atualmente ocupam lugar de destaque no planejamento e execução de operações que envolvam a circulação de mercadorias, tanto em nível local como ao redor do planeta.

O ápice de seu desenvolvimento ocorreu principalmente a partir da Segunda Guerra Mundial, como reforço às novas tecnologias de produção nas empresas industriais, como o Just-in-time (no tempo certo) e Supply Chain Management (gerenciamento da cadeia de suprimentos) (LEITE, 2003).

Ultimamente as empresas perceberam a importância da logística para além de atividades de apoio que não agregavam valor aos produtos. Com a economia, as empresas acordaram e começaram a vê-la como ferramenta necessária à competitividade e à sobrevivência do negócio. Os empresários começaram a olhar seus custos mais detalhadamente e a buscar respostas para perguntas sobre aspectos de localização e de excelência no atendimento aos clientes.

Podemos dizer que a logística é a arte de gerenciar, de forma global e otimizada, o fluxo de movimentos e informações, da origem ao ponto final do processo, atendendo satisfatoriamente ao cliente final com um produto de alto nível de qualidade e competitividade e com custos adequados (PORTAL DA EDUCAÇÃO, 2013).

As empresas já estão preocupadas com alguns custos de cadeia, especialmente os de transporte, distribuição e armazenamento de seus produtos. 
Até a década de 1940, o mundo empresarial era caracterizado por alta produção; baixa capacidade de distribuição; despreocupação com custos; inexistência do conceito de logística empresarial (PORTAL DA EDUCAÇÃO, 2013).

Entre 1950 e 1965, surgiu o conceito de logística empresarial, motivado por uma nova atitude do consumidor; pelo desenvolvimento de análise de custo total; pelo início da preocupação com os serviços ao cliente e de maior atenção com os canais de distribuição.

No período de 1965 a 1980, ocorreu a consolidação de conceitos, emergiu a colaboração decisiva da logística no esforço para aumentar a produtividade da energia, visando compensar o aumento da produção industrial afetada pela crise do petróleo. Deram-se ainda o crescimento dos custos da mão de obra e o aumento dos juros internacionais.

Após a década de 1980, a logística passou a ser influenciada pelos seguintes aspectos: desenvolvimento revolucionário da logística decorrente das demandas ocasionais; globalização; alterações estruturais na economia mundial; desenvolvimento tecnológico (PORTAL DA EDUCAÇÃO, 2013).

\section{A LOGÍSTICA DA AGRICULTURA FAMILIAR NO CEARÁ EM RELAÇÃO AO PNAE}

Por meio das entrevistas realizadas com agricultores familiares individuais e integrantes de uma cooperativa e da observação participante, podem-se verificar as modalidades de logística utilizadas pelos agricultores para suprimento do PNAE nos municípios cearenses.

Cabe ressaltar que, conforme determinação da Lei n. 11.947/2009, pelo menos $30 \%$ do valor dos repasses do FNDE para o PNAE nos municípios devem ser utilizados para a compra de gêneros alimentícios da agricultura familiar.

\footnotetext{
Do total dos recursos financeiros repassados pelo FNDE, no âmbito do PNAE no mínimo $30 \%$ (trinta por cento) deverão ser utilizados na aquisição de gêneros alimentícios diretamente da agricultura familiar e do empreendedor rural ou de suas organizações, priorizando-se os assentamentos da reforma agrária, comunidades indígenas e comunidades quilombolas. (BRASIL, 2009, p. 4).
}

Conforme a Resolução n. 4/2015 do FNDE, esse tipo de aquisição deve ser formalizado por meio de um contrato entre a Entidade Executora (EEx) e os 
fornecedores da agricultura familiar e do empreendedor familiar rural. O ponto de partida do processo é a divulgação e publicação pela EEx de um documento designado como edital de chamada pública, que deve ficar aberto para recebimento dos projetos de venda por período mínimo de 20 dias.

\begin{abstract}
A chamada pública é o procedimento administrativo voltado à seleção proposta específica para a aquisição de gêneros alimentícios provenientes da agricultura familiar e/ou empreendedores rurais ou suas organizações. É um instrumento firmado no âmbito das estratégias de compras públicas sustentáveis, que assegura o cumprimento dos princípios constitucionais da administração pública, ao passo que permite a veiculação de diretrizes governamentais importantes, relacionadas ao desenvolvimento sustentável, ao apoio à inclusão social e produtiva local e à promoção da segurança alimentar e nutricional. Assim, apresenta maior possibilidade de atender às especificidades necessárias à aquisição da agricultura familiar, desde que respeitadas as normas do programa. (BRASIL, 2015, s.p.).
\end{abstract}

Contudo, há dificuldades de aplicação pelas EEx do percentual mínimo acima citado, o que decorre das condições climáticas do Ceará, da limitada capacidade de produção de alimentos em maior escala, do pouco conhecimento dos agricultores familiares em relação às regras do Programa, bem como das limitações de natureza logística.

Os agricultores familiares do estado não produzem o suficiente para abastecer o programa de alimentação escolar durante todo o ano, com raras exceções daqueles que têm acesso à irrigação. Devido ao longo período de escassez de chuvas, até mesmo a produção irrigada de gêneros alimentícios teve queda de produção acentuada nos últimos anos. Todavia, seja por meio de associações e cooperativas, seja mediante grupos isolados ou individualmente, eles conseguem vender parte dos gêneros que produzem alimentação escolar.

As cooperativas e associações, dadas suas condições de organização e posse de maior capital de giro, possuem estrutura de armazenamento e transporte mais adequada, aproximando-se do que se espera de um parâmetro de suprimentos eficiente, conforme definição apresentada por Ramos (2017).

Nesse sentido, há depósitos onde são armazenados gêneros alimentícios não perecíveis, como feijão, milho, farinha de mandioca, dentre outros. A partir desse depósito, começa o processo de fornecimento desses gêneros diretamente para as escolas ou para o depósito central da alimentação escolar no município. 
A distribuição para esses locais é feita por meio de pequenos caminhões ou caminhonetes convencionais, uma vez que esses gêneros não necessitam de transporte refrigerado. A periodicidade de entrega é acertada no contrato de compra, podendo ocorrer de uma só vez, quando a EEx possui condições de armazenamento de toda a compra, ou no formato de entrega segmentada, semanal ou mensal, quando o município ou a escola não possuem um amplo depósito para a guarda dos gêneros até a redistribuição e elaboração do alimento.

No caso dos gêneros entregues às EEx, estas se constituem como um fornecedor intermediário, já que redistribuem os gêneros para as escolas locais, urbanas e rurais, onde são transformados em alimentos, chegando ao consumidor final, os alunos beneficiários do PNAE.

$\mathrm{Na}$ realidade estudada, não se verificaram problemas que acarretem o mau funcionamento ou o não funcionamento da cadeia de suprimentos desse tipo de gêneros. Os problemas identificados estão relacionados a aspectos burocráticos. Um deles é o da não inclusão, pela EEx, do valor referente ao acondicionamento, embalagem, transporte e armazenamento no custo dos alimentos definido pelo contrato de compra. Isso afeta significativamente o lucro do agricultor familiar e consequentemente o impacto no desenvolvimento econômico e social local decorrente da diminuição da renda.

Outro problema identificado em relação à gestão é a ausência do mapeamento dos gêneros da agricultura familiar local, "[...] que deve conter, no mínimo, a discriminação dos produtos locais, quantidade de produção e época de colheita (calendário agrícola)" (BRASIL 2014, p. 9). Esse levantamento, responsabilidade do gestor municipal do PNAE, é essencial e indispensável no planejamento dessa modalidade de compra. Como consequência dessa ausência, pode-se apontar 0 seguinte: a inclusão no planejamento dos cardápios de alimentos não produzidos localmente ou a não inclusão de alimentos da produção local. No primeiro caso, a aquisição dos gêneros alimentícios geralmente fica mais cara, bem como não se cumpre o propósito do PNAE de desenvolvimento econômico e social local previsto em lei, uma vez que se beneficiam produtores de outras regiões ou estados. No segundo, além de não possibilitar a circulação de renda localmente, limita o objetivo de inclusão da alimentação saudável no espaço escolar por meio de produtos in natura, que não 
podem, em geral, ser entregues adequadamente por fornecedores provenientes de locais distantes.

Em se tratando de produtos perecíveis, o estudo identificou problemas que afetam sobremaneira o adequado suprimento do PNAE com produtos in natura por parte de cooperativas, associações, grupo de agricultores ou agricultores isolados. Predominam, nessa cadeia de suprimentos, alguns problemas de suprimento relacionados ao armazenamento e ao transporte: carência de espaços de armazenamento com refrigeração, bem como transporte inadequado.

A maioria dos fornecedores não possui câmaras de refrigeração para depósito dos produtos in natura, que necessitam de refrigeração na etapa inicial de suprimento, que se inicia imediatamente após a coleta dos gêneros. Isso afeta o ritmo e o volume de trabalho do agricultor, pois exige que a colheita seja feita de forma segmentada e de forma imediata à entrega dos gêneros à EEx ou às escolas. Tende a comprometer a qualidade orgânica dos gêneros por meio da colheita em estado de pós-maturação, por vezes gerando prejuízos causados pela recusa de recebimento pela escola ou EEx. Esse problema ocorre também no âmbito da rede de suprimentos de responsabilidade das EEx, porque alguns municípios não possuem depósito central dotado de refrigeração para a guarda dos alimentos até o momento de redistribuição para as escolas ou preparação do alimento. Essa situação se agrava sobremaneira nas escolas localizadas na zona rural, pois a maioria não dispõe de refrigeradores.

Apesar da ocorrência desses problemas, foram identificadas experiências bem-sucedidas de funcionamento da cadeia de suprimentos da agricultura familiar para a alimentação escolar. Nesse caso, encontra-se o fornecimento de gêneros alimentícios, tais como leite in natura, ovos, frutas e hortaliças. Contando com os necessários espaços de depósito e meios de transporte adequados, essa cadeia de suprimentos, considerada adequada conforme definições apresentadas por Ramos (2017), abrange o fornecimento oriundo de cooperativas ou associações de agricultores familiares já estabilizadas em termos de estrutura física e organizacional e de capital de giro. Algumas pertencem a assentamentos de reforma agrária. Mesmo após um longo período de escassez de chuva no Nordeste brasileiro, que vem afetando a região há cinco anos, esses produtores têm conseguido manter o fornecimento para o PNAE, porém em quantidade menor, dada a diminuição de sua capacidade de produção. 
Em síntese, verificou-se, a partir da realidade investigada, que o transporte dos gêneros alimentícios não perecíveis ocorre, em geral, de forma adequada em termos de acondicionamento e tipo de veículo utilizado para a condução da carga. Contudo, a mesma situação não se verifica em relação aos perecíveis, uma vez que há inadequação às regras mínimas de logística, tanto em relação ao depósito inicial do fornecedor como do comprador. Ademais, o meio de transporte se apresenta como inadequado quando 0 gênero necessita de refrigeração, tanto em trânsito como no depósito de destino final.

Em se tratando das dificuldades enfrentadas pela agricultura familiar e suas organizações na venda de gêneros alimentícios para a alimentação escolar, diferentes situações foram identificadas: ausência de informação sobre a produção agrícola local; inexistência do Serviço de Inspeção Municipal (SIM); desconhecimento das regras e legislação do PNAE pelo agricultor familiar e suas organizações; falta de habilidade de elaboração de projetos.

Ausência de informações sobre o que é produzido localmente decorre da falta de mapeamento pela EEx dos produtos da agricultura familiar, o que demonstra a pouca habilidade do gestor municipal na articulação com esses produtores. Consequentemente duas situações podem ocorrer. Em primeiro lugar, os cardápios provavelmente não serão elaborados contemplando essa produção. Sendo assim, parte dos alimentos produzidos pela agricultura familiar local poderá não ser incluída no projeto de compra da EEx. Em segundo lugar, fica comprometido o objetivo de geração de renda local via alimentação escolar.

A inexistência do SIM implica a exclusão da quase totalidade da produção agrícola familiar de alimentos de origem animal da alimentação escolar. Sem esse serviço que certifica as condições sanitárias e higiênicas da produção, processamento e beneficiamento dos alimentos dessa origem, o mel de abelhas, a carne de ovinos e caprinos, o leite, dentre outros, deixam de ser comprados pelo PNAE municipal, consequentemente o equivalente valor financeiro deixa de ser aplicado e de circular no local ou região.

Predomina entre os agricultores familiares e suas organizações o pouco conhecimento acerca das normas que regulam o processo de aquisição de gêneros pela política de alimentação escolar. Desconhecem exigências como estas: obrigação de apresentação de declaração de aptidão ao Pronaf (DAP), que é o instrumento do 
agricultor familiar utilizado para o acesso a políticas públicas; emissão do documento fiscal correspondente ao gênero que pode vender ao PNAE; condições higiênico-sanitárias adequadas que deve cumprir como fornecedor do PNAE.

$O$ agricultor, para vender seus produtos para O PNAE, necessita elaborar, conforme resolução FNDE n. 26/2003, projeto de venda que deve estar adequado às regras da chamada pública elaborada pela EEx. Dado o seu baixo nível de escolarização, bem como a inexistência de formação e/ou capacitação para a elaboração de projetos, os agricultores familiares têm suas possibilidades de venda diminuídas. Em alguns casos, esses produtores têm que contratar o serviço de um projetista, o que acarreta a diminuição de seu lucro. Esse caso é o mais comum entre agricultores familiares fornecedores individuais.

Enfim, o estudo pode identificar as formas de suprimento utilizadas pelos agricultores familiares, explicitando os avanços conseguidos e as dificuldades em relação ao suprimento do PNAE municipal com alimentos provenientes da agricultura familiar, assim como a concretização do objetivo do PNAE de contribuir para o desenvolvimento econômico e social local.

\section{CONSIDERAÇÕES FINAIS}

As reflexões ora empreendidas partiram da seguinte problemática de pesquisa: a logística de transporte dos gêneros alimentícios utilizada pelos agricultores interfere na concretização dos objetivos de desenvolvimento econômico e social local e na efetivação do preceito legal de aplicação mínima de $30 \%$ dos recursos do PNAE na agricultura familiar. Do objetivo de analisar a relação entre a logística empregada pelos agricultores familiares cearenses e a concretização do propósito do PNAE de desenvolvimento econômico e social local, a pesquisa chegou a alguns achados, conforme relataremos a seguir.

A logística utilizada pelos agricultores familiares cearenses no fornecimento de alimentos para o PNAE apresenta problemas principalmente em relação ao transporte e armazenamento dos gêneros perecíveis, porém tal ocorrência não se verifica no fornecimento de gêneros não perecíveis. 
A agricultura familiar enfrenta dificuldades que decorrem da não realização, pelas EEx, no caso os municípios, de mapeamento da produção de alimentos local, uma das etapas fundamentais para a compra de agricultores familiares e empreendedores rurais. Em reforço a essa situação, a inexistência de SIM no município da pesquisa contribui para a não utilização de produtos de origem animal - carnes, ovos, mel de abelha - na alimentação escolar.

O conhecimento dos agricultores acerca da legislação e normas que regulam o fornecimento de alimentos para o PNAE é muito limitado, o que dificulta ou impede sua participação. Além disso, eles não possuem habilidade para elaborar projetos de venda, situação que os deixa vulneráveis à ação de intermediários, como os projetistas, que cobram pela elaboração de projetos, o que concorre para a diminuição do lucro.

$O$ estudo permite afirmar que tanto a logística de fornecimento da agricultura familiar como os aspectos burocráticos e a falta de planejamento contribuem para a não participação adequada dessa categoria de produtores no fornecimento de alimentos para a alimentação escolar, mesmo considerando o percentual mínimo obrigatório de compra determinado pelo FNDE. Assim, a efetivação do objetivo do PNAE de contribuir para o desenvolvimento econômico e social local não se realiza de forma plena.

A pesquisa teve suas limitações, não somente em termos de abrangência, por ter sido de ocorrência local, como também pela dificuldade de análise dos dados decorrente da distância enorme entre os preceitos legais do PNAE, a teoria da logística e a realidade da venda de gêneros pela agricultura familiar. Contudo, mesmo sendo um estudo de caso, os resultados acenam para novas inquietações, que podem gerar outras pesquisas sobre a temática, além de contribuir como um subsídio para ações de pensar o PNAE tendo em vista a melhoria de sua execução.

\section{REFERÊNCIAS}

BARREIRA, M. S. C. A intervenção planejada e o discurso da participação. In: CARVALHO, A. M. P. (Org.). A política da escassez: lutas urbanas e programas sociais governamentais. Fortaleza: Demócrito Rocha, 1991. p. 77-110.

BEZERRA, J. A. B. Do Programa Nacional de Merenda Escolar (1954) ao Programa Fome Zero (2003): rastros do itinerário da política de alimentação escolar no Brasil. In:

Educação \& Formação, Fortaleza, v. 4, n. 11, p. 97-116, maio/ago. 2019

DOI: https://doi.org/10.25053/redufor.v4i11.899

http://seer.uece.br/redufor 
CAVALCANTE, M. J. M.; BEZERRA, J. A. B. (Org.). Biografias, instituições, ideias, instituições e políticas educacionais. Fortaleza: UFC, 2003. p. 449-467.

BEZERRA, J. A. B. Regionalização de cardápios, fortalecimento de economias locais e participação da população na gestão da merenda. Educação em Debate, Fortaleza, v. 2, p. 55-71, 2009.

BRASIL. Aquisição de produtos da agricultura familiar para a alimentação escolar. Brasília, DF: MEC, 2014.

BRASIL. Fundo Nacional de Desenvolvimento da Educação. Dados físicos e financeiros do PNAE. Disponível em: <http://www.fnde.gov.br/programas/alimentacao-escolar/ alimentacao-escolar-consultas/alimentacao-escolar-dados-f\%c3\%adsicos-e-financeirosdo-pnae>. Acesso em: 14 nov. 2016.

BRASIL. Fundo Nacional de Desenvolvimento da Educação. Resolução n. 4. Brasília, DF: MEC, 2015.

BRASIL. Lei n. 11.326, de 24 de julho de 2006. Estabelece as diretrizes para formulação da Política Nacional da Agricultura Familiar e Empreendimentos Familiares Rurais. Diário Oficial [da] República Federativa do Brasil, Poder Executivo, Brasília, DF, 25 jul. 2006.

BRASIL. Lei n. 11.947, de 16 de junho de 2009. Dispõe sobre o atendimento da alimentação escolar e do Programa Dinheiro Direto na Escola aos alunos da educação básica; altera as Leis n. 10.880, de 9 de junho de 2004, n. 11.273, de 6 de fevereiro de 2006, n. 11.507, de 20 de julho de 2007; revoga dispositivos da Medida Provisória n. 2.178-36, de 24 de agosto de 2001, e a Lei n. 8.913, de 12 de julho de 1994; e dá outras providências. Diário Oficial [da] República Federativa do Brasil, Poder Executivo, Brasília, DF, 17 jun. 2009.

BRASIL. Ministério da Educação. Fundo Nacional de Desenvolvimento da Educação. Aquisição de produtos da agricultura familiar para a alimentação escolar. 3. ed. Brasília, DF: MEC, 2017.

COIMBRA, M. A.; MEIRA, J. F. P.; STARLING, M. B. L. Comer e aprender: uma história da alimentação escolar no Brasil. Belo Horizonte: INAE, 1982.

FIGUEIREDO, K.; ARKADER, R. Da distribuição física ao supply chain management: o pensamento, $\mathrm{o}$ ensino e as necessidades de capacitação em logística. Revista Tecnologística, São Paulo, n. 33, p. 16, 1998.

GOMES, F. S.; RIBEIRO, P. C. C. Gestão da cadeia de suprimentos integrada à tecnologia da informação. São Paulo: Thomson Learning, 2004.

GOMES, L. S. A logística de compras de alimentos para o Programa Nacional de Alimentação Escolar: o caso da aquisição de gêneros da agricultura familiar. 2017. 20 f. Trabalho de Conclusão de Curso (Especialização/MBA em Logística Empresarial) - 
Programa de Pós-Graduação em Logística Empresarial, Universidade Estácio de Sá, Fortaleza, 2017.

LEITE, P. R. Logística reversa: meio ambiente e competitividade. São Paulo: Pearson Prentice Hall, 2003.

NOVAES, A. G. Logística e gerenciamento da cadeia de distribuição. Rio de Janeiro: Elsevier, 2007.

PEIXINHO, A. M. L. A trajetória do Programa Nacional de Alimentação Escolar no período de 2003-2010: relato do gestor nacional. Ciência \& Saúde Coletiva, Rio de Janeiro, n. 18, v. 4, p. 909-916, 2013.

PORTAL DA EDUCAÇÃO. Conceitos e teorias sobre logística. Disponível em: <https://www. portaleducacao.com.br/administracao/artigos/31543/conceitos-e-teorias-sobre-logistica>. Acesso em: 25 jan. 2017.

PORTAL DA EDUCAÇÃO. Evolução da logística. Disponível em: <https://www.portal educacao.com.br/administracao/artigos/31571/evolucao-da-logistica>. Acesso em: 6 jan. 2017.

RAMOS, R. Definições de cadeia de suprimentos. Infoescola. Disponível em: <http:// www.infoescola.com/administracao_/definicoes-de-cadeia-de-suprimentos/>. Acesso em: 5 fev. 2017.

\section{Ludmir dos Santos Gomes (Brasil, Ceará, Fortaleza) - Universidade Federal do Ceará (UFC)} Mestrando em Educação pela UFC. Participa do Centro Colaborador em Alimentação e Nutrição do Escolar (Cecane). Professor da área de Comércio Exterior.

Lattes: <http://lattes.cnpq.br/5777586978354401>.

E-mail: <ludmirgomes@hotmail.com>.

José Arimatea Barros Bezerra (Brasil, Ceará, Fortaleza) - Universidade Federal do Ceará (UFC) Pós-Doutor em História pela Universidade Federal do Paraná (UFPR). Coordenador de Gestão do Centro Colaborador em Alimentação e Nutrição do Escolar (Cenane). Professor associado da Faculdade de Educação da UFC.

Lattes: <http://lattes.cnpq.br/8455253726902963>.

E-mail: <jotabarrosbezerra@gmail.com>.

Recebido em 16 de abril de 2018.

Aceito em 15 de outubro de 2018.

Educação \& Formação, Fortaleza, v. 4, n. 11, p. 97-116, maio/ago. 2019

DOI: https://doi.org/10.25053/redufor.v4i11.899

http://seer.uece.br/redufor 